\title{
QUALIDADE EM SERVIÇOS DE TRANSPORTE PÚBLICO URBANO: UMA CONTRIBUIÇÃO TEÓRICA
}

\author{
Paulo Vitor Nascimento de Freitas ${ }^{1}$
}

José Augusto Ribeiro da Silveira ${ }^{2}$

Alexandre Augusto Bezerra da Cunha Castro ${ }^{3}$

\begin{abstract}
RESUMO
O conceito de qualidade está presente há muito tempo na ciência e no senso comum, passando por transformações ao longo dos anos. Em serviços de transporte público urbano, onde ela está presente tanto na causa como nas consequências, o governo tem enfrentado dificuldades em oferecer um serviço de qualidade a uma tarifa justa. Diante desse cenário, este trabalho tem por objetivo fazer uma revisão bibliográfica acerca do conceito de qualidade aplicado aos serviços de transporte público urbano. A metodologia adotada pautou-se em consulta a acervos bibliográficos para busca de contribuições na literatura. O conceito de qualidade, apesar de em geral ser subjetivo, também pode contemplar parâmetros objetivos. Ele é largamente entendido como satisfação do cliente quanto à adequação do produto ao uso, definição que contempla também a conformidade com as especificações. Em serviços de transporte público urbano, a qualidade é afetada por características como o fato de se tratarem de mercados regulamentados, serem intangíveis, sofrerem com grandes oscilações espaciais e temporais de demanda, ocorrerem em ambientes não controlados, entre outros. Conclui-se e recomenda-se, dentre outras coisas, que as avaliações da qualidade em serviços de transporte público urbano valham-se tanto da opinião do usuário (sua percepção) quanto da parte técnica-operacional. Trata-se de uma avaliação integrada e sistêmica que, com foco no usuário e com um pano de fundo técnico, pode oferecer um diagnóstico com maior potencial de correspondência à realidade do que avaliações isoladas.
\end{abstract}

PALAVRAS-CHAVE: Qualidade. Transporte público. Contribuição teórica.

\footnotetext{
${ }^{1}$ Mestrando do Programa de Pós-Graduação em Engenharia Civil e Ambiental da Universidade Federal da Paraíba. Bolsista do Conselho Nacional de Desenvolvimento Científico e Tecnológico (CNPq).paulogeo5@gmail.com.

2 Dr. em Desenvolvimento Urbano pela Universidade Federal de Pernambuco, Professor associado do Departamento de Arquitetura da Universidade Federal da Paraíba. ct.laurbe@gmail.com.

${ }^{3}$ Mestre em Engenharia Civil e Ambiental, Professor Assistente, Departamento de Arquitetura, Centro de Tecnologia da Universidade Federal da Paraíba. alexbccastro@hotmail.com.
} 


\title{
QUALITY IN URBAN PUBLIC TRANSPORT SERVICES: A THEORETICAL CONTRIBUTION
}

\begin{abstract}
The concept of quality is present for a long time in science and common sense, undergoing transformations over the years. In urban public transport services, where it is present in both the cause and the consequences, the government has struggled to offer a quality service at a fair rate. Against this backdrop, this paper aims to make a literature review about the concept of quality applied to urban public transport services. The methodology adopted was marked in consultation with library collections to search contributions in literature. The concept of quality, though generally be subjective, can also include objective parameters. It is widely understood as customer satisfaction as to suitability for use, a definition that also includes compliance with the specifications. In urban public transport services, the quality is affected by features such as the fact of whether they are regulated markets, being intangible, suffer with large spatial variations and temporal demand, occur in an uncontrolled environment, among others. It is concluded and recommended, among other things, that the quality assessments in urban public transport services are worth as much of the user's opinion (perception) as the technical-operational part. It is an integrated and systemic evaluation, focusing on the user and a technical background, can provide a diagnosis with greater potential for correspondence to reality than isolated evaluations.
\end{abstract}

KEYWORDS: Quality. Public transport. Theoretical contribution.

\section{CALIDAD EN SERVICIOS URBANOS DE TRANSPORTE PÚBLICO: UNA CONTRIBUCIÓN TEÓRICA}

\begin{abstract}
RESUMEN
El concepto de calidad está presente desde hace mucho tiempo en la ciencia y el sentido común, sufriendo transformaciones a lo largo de los años. En los servicios de transporte público urbano, donde está presente tanto en la causa y las consecuencias, el gobierno ha luchado por ofrecer un servicio de calidad a un precio justo. En este contexto, el presente trabajo tiene como objetivo hacer una revisión de la literatura sobre el concepto de calidad aplicado a los servicios de transporte público urbano. La metodología adoptada fue marcado en consulta con las colecciones de la biblioteca para buscar contribuciones en la literatura. El concepto de calidad, aunque por lo general ser subjetivo, también puede incluir parámetros objetivos. Es ampliamente entendida como la satisfacción del cliente en cuanto a idoneidad para el uso, una definición que también incluye el cumplimiento de las especificaciones. En los servicios de transporte público urbano, la calidad se ve afectada por las características tales como el hecho de que sean regulados los mercados, siendo intangible, sufren con grandes variaciones espaciales y temporales de la demanda, se producen en un entorno no controlado. Se concluye y recomienda, entre otras cosas, que las evaluaciones de la calidad en los servicios de transporte público urbano valen tanto de la opinión del usuario (percepción) como la parte técnica-operativa. Es una evaluación integral y sistémico, centrado en el usuario y una formación técnica, puede proporcionar un diagnóstico con mayor potencial para la correspondencia a la realidad que las evaluaciones aisladas.
\end{abstract}

PALABRAS CLAVE: Calidad. Transporte público. Contribución teórica. 


\section{INTRODUÇÃO}

O conceito de qualidade está presente há muito tempo na ciência e no senso comum. Ao longo dos anos, no entanto, vem passando por transformações em variadas áreas do conhecimento e se estendendo a muitas outras, influenciado por autores cujas contribuições inspiraram mudanças em diversas organizações, grandes e pequenas, públicas e privadas. Mas apesar de toda a difusão dos trabalhos destes e de outros autores, e a despeito do amadurecimento conceitual que proporcionaram, ainda persistem algumas noções obsoletas que eram comumente utilizadas na primeira metade do século $\mathrm{XX}$, sobretudo no senso comum, não sistematizado.

Aliado a isso, conforme transita e é apropriado por diversos campos científicos e setores do mercado, o conceito pode receber de cada um uma roupagem diferente, mesmo que mantenha um tronco-comum. É o caso, por exemplo, da gestão pública e da gestão privada, cujas características comuns e díspares refletem no conceito e na forma como a qualidade pode ser alcançada. Outro exemplo são as noções de qualidade em produtos e em serviços, que apresentam diferenças substanciais.

Alguns casos são particularmente especiais, como aqueles em que um serviço, ainda que público do ponto de vista jurídico, é operado por empresas privadas por meio do regime de concessão. Como a qualidade é vista nestes casos? Como geri-la e garanti-la? Que papel cada ator envolvido tem no processo? A depender do tipo de serviço em questão, as respostas para essas perguntas vão conter diferenças e semelhanças, em diferentes graus.

Os serviços de transporte público urbano funcionam como uma engrenagem essencial para o funcionamento de cidades grandes e médias do Brasil. No entanto, desde as décadas de 1950 e 1960, quando os ônibus passaram a ser o principal modo de transporte público, passando pela onda de privatização da grande maioria 


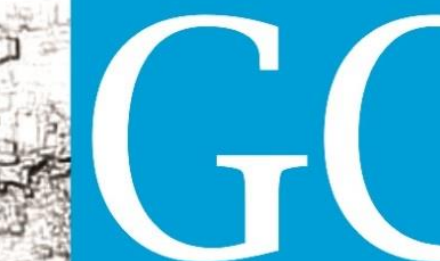

Revista Nacional de

Gerenciamento de Cidades

das empresas de transporte decorrente da política neoliberal e pela Lei das Concessões (Lei Federal no 8.987, de 13 de fevereiro de 1995), o Estado não consegue lidar adequadamente com esse sistema. Isso porque ele não consegue oferecer um serviço de qualidade a uma tarifa justa. Assim, cada vez mais pessoas, na medida em que têm acesso a modos motorizados privados de deslocamento, deixam de utilizar o transporte público e passam a se deslocar na cidade com transporte individual motorizado, alimentando um ciclo vicioso, que tende a degradar sistematicamente o transporte público. Nesse quadro, a qualidade está presente tanto na causa como nas consequências.

Diante desse cenário, este trabalho tem por objetivo fazer uma revisão bibliográfica acerca do conceito de qualidade aplicado aos serviços de transporte público urbano. $O$ interesse por esse estudo teórico teve origem durante as etapas iniciais de pesquisa de mestrado sobre a qualidade do transporte público em João Pessoa, onde se verificou a importância de fazer uma contribuição à discussão do tema. Partir-se-á da noção mais geral do conceito para a específica, focando no conceito em serviços de transporte público urbano por ônibus, por ser o modo público de transporte mais utilizado no Brasil e em grande parte do mundo.

Para o alcance dos objetivos deste trabalho, foram percorridas algumas etapas metodológicas. Inicialmente, foi realizada uma pesquisa bibliográfica, com o intuito de conhecermos alguns trabalhos de autores que têm pesquisado sobre a temática - nesta etapa foram fundamentais consultas ao material bibliográfico dos acervos pessoais dos autores, à periódicos, à Biblioteca Central da Universidade Federal da Paraíba e à teses e dissertações hospedadas em sítios eletrônicos. Em seguida, o material reunido foi apreciado com o objetivo de identificar suas contribuições ao tema. Por fim, foi redigido o texto final, que mescla contribuições próprias dos autores e revisão da literatura. 


\section{QUALIDADE EM SERVIÇOS DE TRANSPORTE PÚBLICO URBANO: ALGUNS CONCEITOS}

\subsection{DEFINIÇÃO DE QUALIDADE}

O conceito de qualidade, de uma forma geral, é subjetivo, e pode ser aplicado tanto a serviços (como é o caso deste trabalho) como também a objetos, indivíduos, etc.. Envolve fatores como necessidade, expectativa e percepção que vão atuar diretamente na sua definição. O Dicionário Priberam da Língua Portuguesa (DPLP) traz pelo menos dez significados para o termo, dentre os quais se podem destacar: "a maneira de ser boa ou má de uma coisa", "superioridade, excelência", "título, categoria", "característica, propriedade" e "atributo, modalidade, virtude, valor".

Mas o fato de o significado mais geral do termo ser subjetivo não implica dizer que não se podem utilizar critérios objetivos na sua definição. Noutras palavras, é possível estabelecer parâmetros objetivo-quantitativos que auxiliem a definição de um produto ou serviço como de boa ou má qualidade, considerando determinados atributos.

A noção de qualidade está presente tanto em avaliações cotidianas informais, oriundas de impressões pessoais e da experiência de cada indivíduo, quanto em órgãos e entidades certificadores de qualidade como a International Organization for Standardization (ISO), o Instituto Nacional de Metrologia, Qualidade e Tecnologia (INMETRO) e a Associação Brasileira de Normas Técnicas (ABNT). Mas as definições utilizadas nesses dois campos - do senso comum e dos especialistas - frequentemente são diferentes.

Paladini (2011) entende que o fato de o termo qualidade ser de uso comum pode decorrer de profundo esforço feito em passado recente para popularizar o termo. Para ele, não se pode dizer que isto seja ruim; o problema está no uso frequente de conceitos incorretos, pois não se pode redefinir de forma intuitiva algo 
Revista Nacional de

Gerenciamento de Cidades

que já é largamente conhecido, nem restringir o uso do termo a situações específicas, uma vez que ele seja de domínio público.

De forma semelhante, Carpinetti (2012) denuncia a confusão conceitual do termo, que existe devido ao subjetivismo associado à qualidade e ao seu uso genérico na representação de coisas distintas. Enquanto para uns a qualidade estaria associada a atributos intrínsecos de um bem (como desempenho técnico ou durabilidade), para outros ela estaria associada à satisfação dos clientes quanto à adequação ao uso.

Pode-se enumerar diversos exemplos de definições errôneas para o termo qualidade. Paladini (2011) traz alguns, além de refletir sobre suas decorrências e possíveis consequências. Uma delas é a que define a qualidade como algo abstrato, sem vida própria, indefinido. Nessa visão, a qualidade é algo inatingível, representando um estado ideal sem contato com a realidade. Ora, sendo um estado ideal inatingível, pode-se deduzir que os esforços para seu alcance são inviáveis e ineficazes, e as decisões de investimento em qualidade podem ser consideradas injustificáveis, devido ao elevado custo que esse esforço representaria. Tal postura também pode conduzir à acomodação.

Outra visão equivocada sobre a qualidade é aquela que a considera sinônimo de perfeição. Quando assim definida, qualidade reflete a realidade de se ter atingido um valor máximo, uma situação que não comporta mais alterações, isto é, melhoramentos (Paladini, 2011). Essa noção choca-se com a própria natureza hedonista do homem, que anseia sempre por padrões de qualidade cada vez mais rigorosos.

Particularmente problemático é considerar a qualidade como uma coisa imensurável, algo puramente subjetivo cuja definição é impossível ser dada com clareza devido à ausência de condições que deem conta de identificar, entender e classificar os muitos modos como cada consumidor a vê (Paladini, 2011). Esse entendimento reduz a qualidade a um mero sentimento, como se fosse o único critério capaz de avaliar, ainda que subjetivamente, a qualidade. 
Imagine-se, então, a qualidade como a capacidade que um produto ou serviço tenha de sair conforme seu projeto, sem considerar a relação real entre o projeto e os possíveis usuários daquilo que se projetou (como se, por exemplo, qualidade se resumisse a ter fábricas capazes de desenvolver os produtos projetados, ou uma equipe capaz de operar um serviço fielmente de acordo com o que foi planejado). Ou, então, como requisito mínimo de funcionamento, ou seja, uma visão que a nivela por baixo e que confunde o mero funcionamento do produto/serviço com satisfação do consumidor. Ou, ainda, o que parece ser o pior equívoco conceitual: a noção da qualidade como tarefa dos especialistas no assunto, o que torna os demais envolvidos no serviço ou fabricação isentos do esforço pela qualidade (Paladini, 2011).

Entretanto, é importante destacar que essas noções compõem o conceito básico de qualidade. O maior equívoco está em considerá-los isoladamente, como se por si só algum desses elementos fosse qualidade. Em outras palavras, qualidade não é só algo puramente abstrato, ou sinônimo de perfeição, ou um mero sentimento imensurável, ou a capacidade de executar o que foi planejado, ou um requisito mínimo de funcionamento, etc. Qualidade envolve múltiplos elementos e cada um deles têm um papel, não podendo ser considerados isolados. Focar atenção exagerada em algum deles em detrimento ou desconsideração de outros pode fragilizar a organização (Paladini, 2011).

Até o início dos anos 1950, a qualidade era considerada sinônima de perfeição técnica, resultado de um projeto e fabricação responsáveis por conferir essa propriedade. A partir da década de 1950 percebeu-se que, para além do grau de perfeição técnica, a noção de qualidade deveria estar associada também ao grau de adequação aos requisitos do cliente. Assim, "qualidade então passou a ser conceituada como satisfação do cliente quanto à adequação do produto ao uso" (Carpinetti, 2011, p. 6). Este entendimento, que contempla adequação ao uso e conformidade com as especificações do produto, tem sido predominante nas últimas 


\section{Revista Nacional de}

Gerenciamento de Cidades

décadas, representa a tendência futura (Carpinetti, 2012) e será adotado neste trabalho.

Denomina-se qualidade percebida a relação entre a expectativa e a percepção por parte do cliente, de tal modo que se pode dizer que a satisfação existirá quando a percepção superar a expectativa e a insatisfação será resultado do inverso (Carpinetti, 2012). Las Casas (1999) tem um entendimento semelhante dessa relação ao tratar da qualidade em serviços (tema do próximo item), embora divirja com relação à linha que separa a satisfação da insatisfação. $O$ autor também considera que a relação entre a expectativa que se tem em relação a um serviço e o resultado que se obtém do mesmo responde pela qualidade que lhe é atribuída. Quando o resultado é inferior à expectativa, há insatisfação e diz-se que o serviço é de má qualidade; quando o resultado é igual ou superior à expectativa, o sentimento gerado é de satisfação, que atribui avaliação positiva ao serviço, sendo ele, portanto, de qualidade. No caso de o resultado superar a expectativa, especificamente, ele ainda diz que foi atingida a excelência em serviços.

\subsection{QUALIDADE EM SERVIÇOS}

Apesar de ambas serem área de atuação da gestão da qualidade, produto e serviço possuem características distintas. Primeiramente, ao contrário do caso industrial, na área de prestação de serviços não há a possibilidade de se separar, de forma nítida, o processo produtivo da prestação do serviço, pois ambos se confundem - ou seja, não há como definir onde termina a produção e começa o consumo, eles são simultâneos. É por isso que o foco fundamental da gestão da qualidade nesse ambiente é a interação com o usuário, pois é nesse processo interativo que a qualidade aparece (Paladini, 2011).

Para entender o conceito de qualidade em serviços é fundamentalmente necessário definir o que seja serviço. Pode-se dizer que serviços "são atos, ações, desempenho" (Las Casas, 1999, p. 14). Essa definição, genérica, engloba todas as 


\section{Revista Nacional de}

Gerenciamento de Cidades

categorias de serviços, sejam eles agregados a um bem ou não. A importância de entender o serviço como ato e desempenho é que isto denuncia sua intangibilidade e mostra que, embora possa acompanhar (ou não) um bem, o objeto de transação é sempre uma ação, um processo.

Las Casas (1999, p. 16) afirma que a prestação de um serviço pode gerar satisfação ou insatisfação nos clientes, de modo que se pode dizer que o produto final de um serviço é um sentimento, que por sua vez varia não só de acordo com a conformidade técnica do objeto de transação, mas também conforme as expectativas dos clientes. Baseado em Karl Albrecht, o autor também diz que qualidade em serviços "é a capacidade que uma experiência ou qualquer outro fator tenha para satisfazer uma necessidade, resolver um problema ou fornecer benefícios a alguém".

Bertozzi e Lima Jr. (1998) verificam que existe uma ampla literatura dedicada à discussão do tema que, com pontos mais ou menos comuns ou divergentes, oferecem definições para o conceito de qualidade em serviços. Dois elementos importantes podem ser extraídos das definições listadas pelos autores: um é a presença de palavras-chave como expectativa, impressão e percepção nas definições, todas relacionadas aos clientes/consumidores; outro elemento é o fato de que em parte significativa delas aparece o fator comparativo - aquele que relaciona $o$ serviço em questão com outros disponíveis. O primeiro elemento mostra que as definições seguem a linha de entendimento predominante e em tendência, enquanto o segundo evidencia que a qualidade de um determinado serviço, na visão de alguns autores, não é avaliada isolando este das alternativas de serviço disponíveis, mas considerando a relação de inferioridade/superioridade entre eles. Ou seja, comparando-os.

Não é possível, no caso do serviço, empregar ações corretivas, mas apenas preventivas, baseadas em ações análogas ocorridas no passado (Paladini, 2011). Por exemplo, uma fabricante pode solicitar a devolução de um lote ou de uma linha 
Revista Nacional de

Gerenciamento de Cidades

inteira de seus produtos (recall) se, por exemplo, constatar problemas relativos à segurança do mesmo. Essa ação não pode ser feita na prestação de um serviço.

O serviço não pode ser estocado. Essa impropriedade, quando não é devidamente considerada, provoca problemas de aumento de custos e perda de qualidade. Isso requer um modelo de gestão que adeque a oferta à demanda (Paladini, 2011). Para Las Casas (1999), o fato de o serviço não poder ser estocado está ligado ao aspecto da inseparabilidade, sendo os serviços prestados geralmente quando vendedor e comprador então frente a frente.

Por haver presença física do cliente no ato de produção do serviço pode-se falar, então, do cliente como "co-produtor", pois o atendimento pleno envolve expectativas expressas por ele durante o processo. O feedback (retorno do usuário sobre o que foi adquirido) é imediato. Trata-se de um mecanismo que permite rápida realimentação, mas que, em contrapartida, requer extrema flexibilidade, criatividade e capacidade de adaptação (Paladini, 2011).

\subsection{QUALIDADE EM SERVIÇOS DE TRANSPORTE PÚBLICO URBANO}

Pode-se definir Transporte como o deslocamento intencional de pessoas e/ou mercadorias ou, ainda, conforme Magalhães, Aragão e Yamashita (2014, p. 8), "o deslocamento intencional de um objeto material, palpável". Ferraz e Torres (2004), por sua vez, definem "transporte urbano" como o deslocamento de pessoas e produtos realizados no interior das cidades.

A Política Nacional de Mobilidade Urbana (Lei no 12.587 de 3 de janeiro de 2012), em seu artigo 4을 define transporte urbano como "conjunto dos modos e serviços de transporte público e privado utilizados para o deslocamento de pessoas e cargas nas cidades". Esta mesma lei classifica os serviços de transporte urbano da seguinte maneira:

Quanto ao objeto: de passageiros e de cargas;

Quanto à característica do serviço: coletivo e individual; 


\section{Revista Nacional de}

Quanto à natureza do serviço: público e privado;

Interessa, para este trabalho, o serviço de transporte público coletivo de passageiros, também chamado na literatura de Sistema de Transporte Público de Passageiros (STPP), ou ainda simplesmente "transporte público urbano". O transporte público coletivo é definido, pelo mesmo documento, como "serviço público de transporte de passageiros acessível a toda a população mediante pagamento individualizado, com itinerário e preços fixados pelo poder público" (BRASIL, 2012).

Oliveira (2003) ressalta que a prestação de serviços públicos, por ser essencial ao interesse coletivo, é regida por cinco princípios gerais elencados pela doutrina, a saber:
a) Generalidade - serviço igual para todos;
b) Eficiência - atualização permanente do serviço e segurança para o usuário;
c) Modicidade - o valor da tarifa não deve ser oneroso demais;
d) Cortesia - o usuário deve ser tratado com urbanidade; e
e) Continuidade - o serviço deve ser permanentemente oferecido ao usuário.

A larga maioria dos sistemas de transporte público urbano é operada por meio do regime de concessão. A Lei de Concessões, em seu art. 6ํㅡ, afirma que "Toda concessão ou permissão pressupõe a prestação de serviço adequado ao pleno atendimento dos usuários". $O \S 2^{\circ}$ do mesmo artigo define serviço adequado como aquele "que satisfaz as condições de regularidade, continuidade, eficiência, segurança, atualidade, generalidade, cortesia na sua prestação e modicidade das tarifas" (BRASIL, 1995).

Uma das características dos serviços de transportes é a de que, em muitos casos, eles são executados em mercados regulamentados. O serviço de transporte público urbano é um exemplo disso. Nesse sistema existe a figura do "usuário cativo", isto é, aquele que, em geral, desloca-se cotidianamente usando apenas o modal ônibus, seja por restrições orçamentárias ou por falta de outras opções 


\section{Revista Nacional de}

Gerenciamento de Cidades

modais. Percebe-se que a importância da qualidade nestes mercados só tende a crescer à medida que aumenta a consciência e o poder de pressão dos usuários. Em alguns casos a busca da qualidade está vinculada à imagem da empresa prestadora do serviço público (Fontes Lima, 1995), bem como à imagem do órgão regulamentador.

Outra característica é a de que os serviços de transportes são vendidos para depois serem produzidos e consumidos. $O$ importante, nesse caso, é o desempenho obtido e não a posse, já que não há tangibilidade (Fontes Lima, 1995).

É verdade que o processo de prestação do serviço de ônibus, intangível, se dá por meio de instrumentos tangíveis - produtos, como os ônibus. Contudo, podese dizer que não há, propriamente, um consumo desses produtos pelo usuário, mas um consumo do serviço que é prestado por meio deles. Embora o uso do produto pelo contratante do serviço cause desgaste do mesmo, é importante entender que o que está sendo feito é a troca de algo que é, ao mesmo tempo, produzido e consumido: o serviço de transporte.

No entendimento de Las Casas (1999), no setor de prestação de serviços, o objeto de comercialização é uma combinação de componentes tangíveis e intangíveis que variam de proporcionalidade. O espectro mercadorias-serviço é composto desde mercadorias relativamente puras (como os alimentos prontos), passando por serviços híbridos (como as lanchonetes) e chegando a serviços relativamente puros, como o de baby-sitter. Neste espectro, o transporte aéreo, por exemplo, ocupa uma posição intermediária entre os híbridos e os relativamente puros.

A propriedade que um serviço tem de não separar produção e consumo é facilmente visualizada no caso dos transportes. Essa característica, que cria a necessidade (nem sempre adequadamente atendida) de monitoração da qualidade em tempo real, traz variabilidades aos processos, resultado da participação do usuário na prestação do serviço (Fontes Lima, 1995). Em serviços de transporte público, por exemplo, o ônibus não parará em determinado ponto se algum usuário, 


\section{Revista Nacional de}

Gerenciamento de Cidades

seja no interior do veículo ou fora dele, não solicitar. O não atendimento da solicitação do usuário gera insatisfação e, logo, implica em queda na percepção da qualidade.

Em João Pessoa, uma matéria veiculada no Portal G1 Paraíba, no dia 20 de agosto de 2014, mostrou que, àquela época, estavam ocorrendo situações em que alguns motoristas de ônibus não atendiam as solicitações de usuários idosos por parada, além de não oferecerem tempo suficiente para que eles pudessem se acomodar no interior do veículo antes da aceleração do mesmo. Ao entrevistar alguns usuários que passaram pela situação, foi claramente demonstrada a insatisfação deles em relação ao problema.

No serviço de transporte público urbano costumam existir grandes oscilações de demanda, isto é, flutuações temporais e desbalanceamentos espaciais tanto em termos de intensidade quanto em termos de frequência, o que cria dificuldades quanto ao dimensionamento de capacidades dos sistemas de prestação de serviços e traz ineficiência e impactos aos padrões de qualidade. Para minimizar os efeitos destes desbalanceamentos, Fontes Lima (1995) sintetiza as estratégias utilizadas em: as que atuam sobre a demanda do sistema procurando alterá-la, como determinadas políticas tarifárias e incentivos promocionais para desenvolvimento de demanda de entre-pico; as que atuam junto à oferta, buscando atender ao pico de demanda; e as que propõem a convivência com a baixa qualidade dos níveis do serviço em determinados horários. No caso desta última, se, por um lado, ela promove economia de recursos do operador do serviço, por outro não poupa consumo de tempo e esforços dos usuários.

Sabe-se que as operações de transporte são sistemas abertos por contarem com a participação dos clientes. Mas, além disso, tem-se também que as atividades dos serviços de transportes são realizadas em ambientes não controlados, como 0 espaço aéreo, o mar, as ruas, as cidades, etc., o que não ocorre com outros serviços e com a manufatura. Esta característica torna este tipo de serviço especialmente vulnerável à ocorrência de eventos extrínsecos que podem degradar 


\section{Revista Nacional de}

Gerenciamento de Cidades

a qualidade do serviço oferecido. No caso do transporte público por ônibus, por exemplo, pode-se citar o congestionamento urbano como um evento que impacta negativamente na qualidade (Fontes Lima, 1995).

O transporte não está desconectado de outras atividades. Para Fontes Lima (1995, p. 69), "sendo o transporte um meio para a realização de muitas atividades, ele se torna participante e dependente de uma rede de relacionamentos entre empresas e/ou atividades bem como suas demandas são derivadas de outras demandas." Por exemplo, em se tratando do transporte público, a demanda pelo deslocamento é resultado de outras, como a de uma empresa que conta com o trabalho presencial de seus funcionários e as demandas por serviços de saúde, educação e lazer, em grande parte dos casos alcançados apenas por meio do deslocamento. Assumir esta característica como verdadeira é entender que o transporte faz parte de uma cadeia de eventos e reconhecer que existe a necessidade de uma abordagem sistêmica que vise a maior integração entre as atividades participantes dessa rede. Um sistema de transporte público urbano que não tem uma operação adequada das linhas de ônibus alimentadoras pode prejudicar o transporte metroviário, por exemplo, o que degrada sistematicamente a qualidade (Fontes Lima, 1995). Políticas de transporte integradas ao uso do solo são exemplos de ações que partem do reconhecimento dessa característica.

Tendo em vista a definição de qualidade percebida, e considerando que, para Lima Jr. (1995 apud Bertozzi e Lima Jr., 1998, p. 54) a qualidade no setor de transportes significa "a qualidade percebida pelos usuários e demais interessados, de forma comparativa com as demais alternativas de serviço existentes", pode-se fazer a pergunta: em transportes, existe qualidade que não seja a percebida?

Las Casas (1999) oferece um entendimento que ajuda na solução dessa questão. Para ele, em serviços, existem dois componentes de qualidade: 0 operacional (ou qualidade real), que é o serviço propriamente dito, isto é, a forma como de fato ele é prestado, o que deve pressupor conformidade com princípios de ordem técnica; e a percepção, que é a forma como a prestação do serviço foi 
Revista Nacional de

Gerenciamento de Cidades

percebida pelo cliente. $\mathrm{O}$ autor defende a necessidade de considerar ambos os componentes no processo de avaliação da qualidade, mas aconselha que se comece sempre por aquilo que o cliente considera mais importante.

Entende-se, então, que avaliar o componente operacional da qualidade é diferente de percebê-la (captação intuitiva de estímulos exteriores baseada nos princípios de similaridade, proximidade e continuidade). Tomando como verdadeiro o entendimento de que qualidade contempla adequação ao uso e conformidade com as especificações, é possível dizer que ambas as formas de avaliar a qualidade fazem parte dessa mesma noção, mais completa. Nesse sentido, a definição de qualidade para o transporte público dada por Lima (1994, apud Bertozzi e Lima Jr., 1998, p. 54) parece contemplar bem este entendimento, pois diz que "a qualidade se traduz na adequação do transporte à necessidade do usuário, ponderando entre a sua expectativa e a avaliação técnica das características e atributos de composição da qualidade". Ou seja, é preciso ponderar a avaliação feita pelo usuário com a avaliação técnica.

\section{CONSIDERAÇÕES FINAIS}

Com o estudo, percebeu-se que lidar com qualidade em serviços de transporte público urbano requer um esforço inicial para entendimento do termo que é essencial para se evitar equívocos conceituais que possam comprometer o desenvolvimento do trabalho. É preciso, quando se pretende trabalhar com este tema, desmistificar algumas noções equivocadas trazidas do senso comum e/ou heranças de conceitos obsoletos.

A grande maioria dos trabalhos lidos mostrou que, apesar de algumas discordâncias pontuais, o conceito de qualidade aparece sempre centrado na satisfação do cliente. Contudo, evidenciou também a importância da avaliação técnica como componente essencial para se fazer ponderações. Ou seja, o mais recomendável é que as avaliações da qualidade em serviços de transporte público 


\section{Revista Nacional de}

Gerenciamento de Cidades

urbano valham-se tanto da opinião do usuário (sua percepção) quanto da parte técnica-operacional. Trata-se de uma avaliação integrada e sistêmica que, com foco no usuário e com um plano de fundo técnico, pode oferecer um diagnóstico com maior potencial de correspondência à realidade do que avaliações isoladas.

Importante salientar que tal visão não busca, de nenhuma maneira, descreditar metodologias pautadas em avaliações exclusivamente técnicas ou de opinião, por entender tratar-se de uma questão de delimitação de objetivos e de método. Contudo, vem destacar que, quando a eles são acrescentadas e integradas informações de cunho técnico - quando se tratar de uma pesquisa de opinião - ou de opinião - quando de cunho técnico -, a carga de subjetividade/objetividade é relativizada e a avaliação aproxima-se mais do conceito de qualidade tal qual foi visto aqui.

\section{REFERÊNCIAS}

BERTOZZI; Patrícia Pacheco; LIMA JR., Orlando Fontes. A qualidade no serviço de transporte público sob as óticas do usuário, do operador e do órgão gestor. Revista dos Transportes Públicos - ANTP. Ano 21, 4ํtrimestre, 1998.

BRASIL. Lei no 8.987 de 13 de fevereiro de 1995. Dispõe sobre o regime de concessão e permissão da prestação de serviços públicos . Disponível em: <http://www.planalto.gov.br/ccivil_03/leis//8987 cons.htm> Acesso em: 17/08/2014.

BRASIL. Lei no 12.587 de 3 de janeiro de 2012. Institui as diretrizes da Política Nacional de Mobilidade Urbana. Disponível em: <http://www.planalto.gov.br/ccivil_03/_ato20112014/2012/lei/l12587.htm> Acesso em: 08/04/2015.

CARPINETTI, Luiz C. R.. Gestão da qualidade ISSO 9001: 2008: princípios e requisitos. 4. Ed. São Paulo: Atlas, 2011.

Gestão da qualidade: conceitos e técnicas. - 2. Ed. - São Paulo: Atlas, 2012.

FERRAZ, Antônio Clóvis "Coca" Pinto; TORRES, Isaac Guillermo Espinosa. Transporte público urbano. São Paulo: Rima, 2004.

FONTES LIMA, Orlando Jr. Qualidade em serviços de transportes: conceituação e procedimento para diagnóstico. Escola Politécnica da Universidade de São Paulo - Departamento de Engenharia de Transportes: São Paulo, 1995. 


\section{Revista Nacional de}

Gerenciamento de Cidades

LAS CASAS, Alexandre Luzzi. Qualidade total em serviços: conceitos, exercícios, casos práticos. 3. Ed. São Paulo: Atlas, 1999.

MAGALHÃES, Marcos Thadeu Queiroz; ARAGÃO, Joaquim José Guilherme de; YAMASHITA, Yaeko. Definição de transporte: uma reflexão sobre a natureza do fenômeno e objeto da pesquisa e ensino em transportes. Transportes, v. 22, n. 3, 2014.

OLIVEIRA, Jairo Garay Ribeiro de. A importância do sistema de transporte coletivo para o desenvolvimento do município de Campo Grande-MS. Universidade Católica Dom Bosco: Campo Grande, 2003.

PALADINI, Edson Pacheco. Gestão da Qualidade: teoria e prática. - 2. Ed. - São Paulo: Atlas, 2011.

PRIBERAM. Dicionário de Língua Portuguesa. Disponível em: <http://www.priberam.pt/dlpo/>. Acesso em: 30/03/2015. 